\title{
Nanostructured Polyphenols-Mediated Coating: A Versatile Platform for Enzyme Immobilization and Micropollutant Removal
} Fangfang Zhou, ${ }^{\dagger, \S}$ Jianquan Luo, ${ }^{*}, \dagger$, Siqing Song, ${ }^{\dagger, \S}$ Yinhua Wan ${ }^{*}, \dagger, \S$

†State Key Laboratory of Biochemical Engineering, Institute of Process Engineering, Chinese Academy of Sciences, Beijing 100190, PR China

\$School of Chemical Engineering, University of Chinese Academy of Sciences, Beijing 100049, PR China

*Corresponding author (Tel: +010-62543301, email: jqluo@ipe.ac.cn,yhwan@ipe.ac.cn)

S1. Alginate/chitosan/montmorillonite (SA/CS/MON) microspheres preparation.

S2. Enzyme assay.

S3. Micropollutants determination.

S4. Characterizations of nylon membranes with TA-APTES coating and enzyme loading.

\section{S1. SA/CS/MON microspheres preparation.}

The SA/CS/MON microspheres were prepared according to our previous work ${ }^{1} .2 \% \mathrm{SA}$ solution was prepared by dissolving $2.0 \mathrm{~g} \mathrm{SA}$ in $100 \mathrm{~mL}$ deionized water. The $\mathrm{CS}^{-} \mathrm{CaCl}_{2}$ mixed gelling solution was prepared as follows: $2.22 \mathrm{~g} \mathrm{CaCl}_{2}$ and $1 \mathrm{~g} \mathrm{CS}$ were dissolved in $100 \mathrm{~mL} 2 \%$ acetic acid solution. $5 \mathrm{~mL}$ SA solution with MON (5 g/L) was dropped into $20 \mathrm{~mL}$ mixed gelling solution through a $0.45 \mathrm{~mm}$ syringe needle at a dropping rate of $0.1 \mathrm{~mL} / \mathrm{min}$. The microspheres 
were cured for $30 \mathrm{~min}$ in the gelling solution at room temperature with gentle stirring, and then the microspheres were filtered, rinsed with deionized water to obtain SA/CS/MON microspheres.

\section{S2. Enzyme Assay.}

\section{Lipase.}

The catalytic activity of lipase was measured by the hydrolysis of p-NPP in acetate buffer (10 $\mathrm{mM}, \mathrm{pH} 6.0)^{2}$. Free or immobilized enzyme was added into the p-NPP solution $(20 \mathrm{~mL}, 2.5 \mathrm{mM})$ at $35{ }^{\circ} \mathrm{C}$. The absorbance change of the hydrolysis product was measured at $410 \mathrm{~nm}$. One unit of lipase catalytic activity (U) was defined as the enzyme amount generating $1 \mu \mathrm{mol}$ of p-NP per minute under the assay conditions $\left(25^{\circ} \mathrm{C}, \mathrm{pH} 6.0\right)$.

\section{Pepsin.}

The catalytic activity of pepsin was measured by hydrolyzing Bovine serum albumin (BSA) in acetate buffer $(10 \mathrm{mM}, \mathrm{pH}=4.0)^{3}$. Free or immobilized enzyme was added into the BSA solution $(20 \mathrm{~mL}, 0.2 \mathrm{mM})$ at $35^{\circ} \mathrm{C}$ for $20 \mathrm{~min}$. Then, the enzymes and undigested BSA were precipitated with trichloroacetic acid (10\%). After centrifugation at $10000 \mathrm{rpm}$ for $15 \mathrm{~min}$, the absorbance of the hydrolysis product was measured at $280 \mathrm{~nm}$. The concentration of tyrosine could be obtained based on the prepared standard curve. One unit of the pepsin catalytic activity (U) was defined as the enzyme amount generating $1 \mu \mathrm{mol}$ of tyrosine per minute under the assay conditions $\left(25^{\circ} \mathrm{C}\right.$, pH 4.0).

\section{Laccase.}

The catalytic activity of laccase was determined using ABTS as the substrate ${ }^{4}$. Free or immobilized enzyme was added into ABTS solution $(20 \mathrm{~mL}, 1 \mathrm{mM})$ prepared with acetate buffer (10 mM, pH 5.0). The absorbance change of the oxidation product was measured at $420 \mathrm{~nm}$. One unit of the laccase catalytic activity (U) was defined as the enzyme amount consuming $1 \mu \mathrm{mol}$ of ABTS per minute under the assay conditions $\left(25^{\circ} \mathrm{C}, \mathrm{pH} 5.0\right)$.

\section{Invertase.}

The catalytic activity of invertase was measured by using 3,5-dinitrosalicylic (DNS) method ${ }^{5}$. Free or immobilized enzyme was added into sucrose solution $(20 \mathrm{~mL}, 2 \mathrm{mM})$ prepared with acetate buffer $(10 \mathrm{mM}, \mathrm{pH} 5.0)$. After incubation at $30^{\circ} \mathrm{C}$ for $10 \mathrm{~min}$, the reaction was stopped by adding $10 \mathrm{~mL}$ of the DNS reagent and heated in a boiling water bath for $2 \mathrm{~min}$, and then the 
samples were cooled down to room temperature. The absorbance change of the reducing sugar residues was measured at $540 \mathrm{~nm}$. One unit of the invertase catalytic activity (U) was defined as the amount generating $1 \mu \mathrm{mol}$ of reducing sugar residues per minute under the assay conditions $\left(25^{\circ} \mathrm{C}, \mathrm{pH} 5.0\right)$

\section{S3. Micropollutants determination.}

Bisphenol A (BPA).

BPA concentrations in the permeate and final retentate were measured by high-performance liquid chromatography (HPLC) (Shimadzu, Japan) installed with a UV-visible detector (SPD-20A, Japan) and a C18 HPLC column (ZORBAX SB-C18, $250 \mathrm{~mm} \times 4.6 \mathrm{~mm}$ i.d.; $5 \mu \mathrm{m}$; Agilent, U.S.A.). Isocratic elution with 50\% HPLC-grade water and 50\% acetonitrile (V/V) were used as mobile phase for HPLC analysis at a flow rate of $1.0 \mathrm{~mL} / \mathrm{min} .50 \mu \mathrm{L}$ sample was injected and the detection wavelength was set at $278 \mathrm{~nm}$ for each analysis. The temperature of column oven was $40{ }^{\circ} \mathrm{C}$. All the samples were filtrated by a $0.22 \mu \mathrm{m}$ filter to remove all the insoluble substance before HPLC analysis. The BPA detection limit in this protocol is $10 \mu \mathrm{g} / \mathrm{L}^{6}$.

\section{2,4,6-trichlorophenol (2,4,6-TCP).}

Isocratic elution with 30\% HPLC-grade water and 70\% acetonitrile (V/V) were used as mobile phase for HPLC analysis at a flow rate of $0.9 \mathrm{~mL} / \mathrm{min} .10 \mu \mathrm{L}$ sample was injected and the detection wavelength was set at $200 \mathrm{~nm}$ for each analysis. The temperature of column oven was $35^{\circ} \mathrm{C}$. The 2,4,6-TCP detection limit in this protocol is $10 \mu \mathrm{g} / \mathrm{L}$. The other steps are the same as in the BPA detection method?

\section{Aflatoxin B1 (AFB1).}

AFB1 concentration was measured by HPLC (Agilent, U.S.A.) installed with a Fluorescence Detector (FLD) (Agilent, U.S.A.) and a C18 HPLC column (ZORBAX SB-C18, $250 \mathrm{~mm} \times 4.6 \mathrm{~mm}$ i.d.; $5 \mu \mathrm{m}$; Agilent, U.S.A.). 50\% HPLC-grade water and 50\% acetonitrile $(\mathrm{V} / \mathrm{V})$ were used as mobile phase for HPLC analysis at a flow rate of $0.8 \mathrm{~mL} / \mathrm{min}$. AFB1 is detected by FLD with an excitation wavelength of $365 \mathrm{~nm}$ and an emission wavelength of $440 \mathrm{~nm}$. The injection volume was $50 \mu \mathrm{L}$ and the temperature of column oven was $30{ }^{\circ} \mathrm{C}$. The AFB1 detection limit in this protocol was $5 \mu \mathrm{g} / \mathrm{L}$. The other steps are the same as in the BPA detection method $^{1}$. 


\section{Deoxynivalenol (DON).}

Isocratic elution with $90 \%$ HPLC-grade water and $10 \%$ acetonitrile $(\mathrm{V} / \mathrm{V})$ were used as mobile phase for HPLC analysis at flow rate of $0.8 \mathrm{~mL} / \mathrm{min} .20 \mu \mathrm{L}$ sample was injected and the detection wavelength was set at $218 \mathrm{~nm}$ for each analysis. The temperature of column oven was $25^{\circ} \mathrm{C}$. The DON detection limit in this protocol is $10 \mu \mathrm{g} / \mathrm{L}$. The other steps are the same as in the BPA detection method.

\section{Tetracycline (TC).}

Isocratic elution with $20 \%$ acetonitrile, $10 \%$ methanol and $70 \%$ oxalic acid solution $(10 \mathrm{mM})$ $(\mathrm{V} / \mathrm{V} / \mathrm{V})$ were used as mobile phase for HPLC analysis at flow rate of $1.0 \mathrm{~mL} / \mathrm{min} .100 \mu \mathrm{L}$ sample was injected and the detection wavelength was set at $350 \mathrm{~nm}$ for each analysis. The temperature of column oven was $25^{\circ} \mathrm{C}$. The TC detection limit in this protocol is $10 \mu \mathrm{g} / \mathrm{L}$. The other steps are the same in the BPA detection method.

\section{S4. Characterization of Nylon Membrane with TA-APTES Coating and Enzyme Loading.}

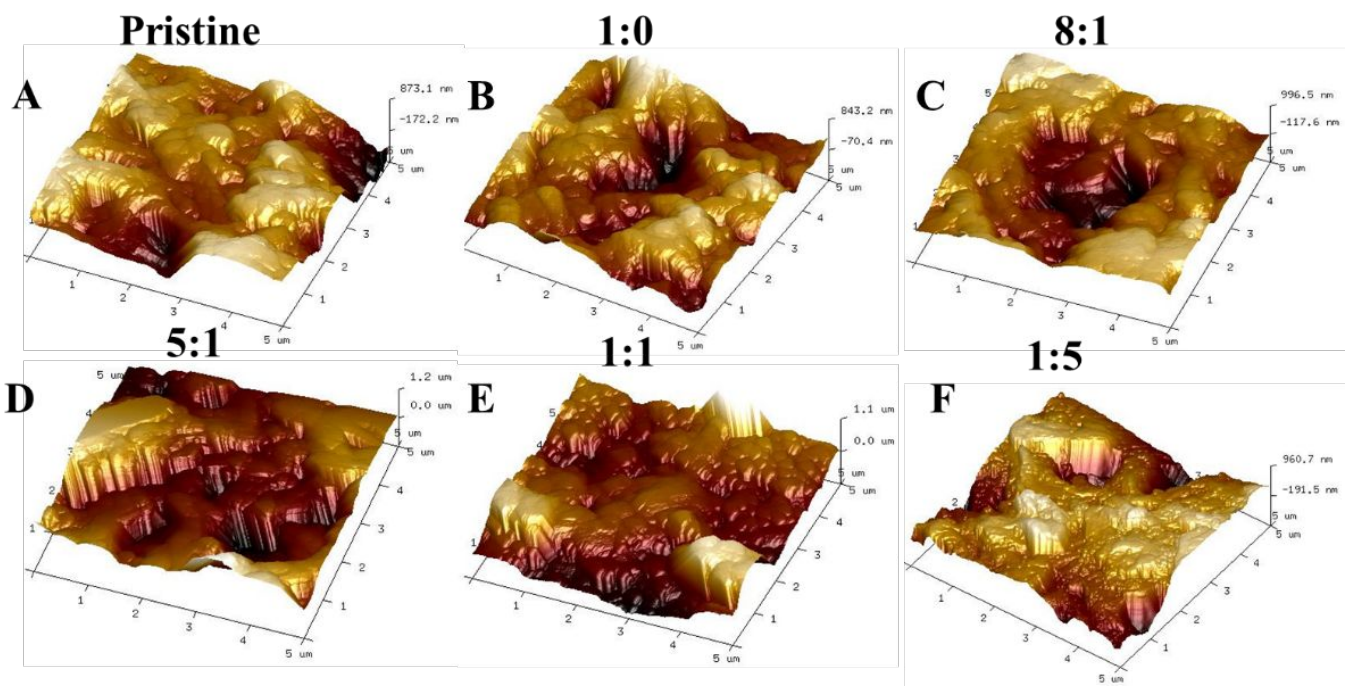

Figure S1. AFM surface images of (A) pristine nylon membrane and TA-APTES coated membranes with different TA/APTES volume ratios: (B) 1:0, (C) 8:1, (D) 5:1, (E) 1:1, (F)1:5.

Table S1 Surface roughness $\left(\mathrm{R}_{\mathrm{q}}=\right.$ mean square roughness $)$ for different membranes

\begin{tabular}{ccccccc}
\hline Membrane & Pristine & $1: 0$ & $8: 1$ & $5: 1$ & $1: 1$ & $1: 5$ \\
\hline $\mathrm{R}_{\mathrm{q}}(\mathrm{nm})^{\mathrm{a}}$ & 303 & 248 & 336 & 341 & 289 & 326 \\
\hline
\end{tabular}

${ }^{a}$ refers to surface roughness for pristine nylon membrane and TA-APTES coated membranes with 

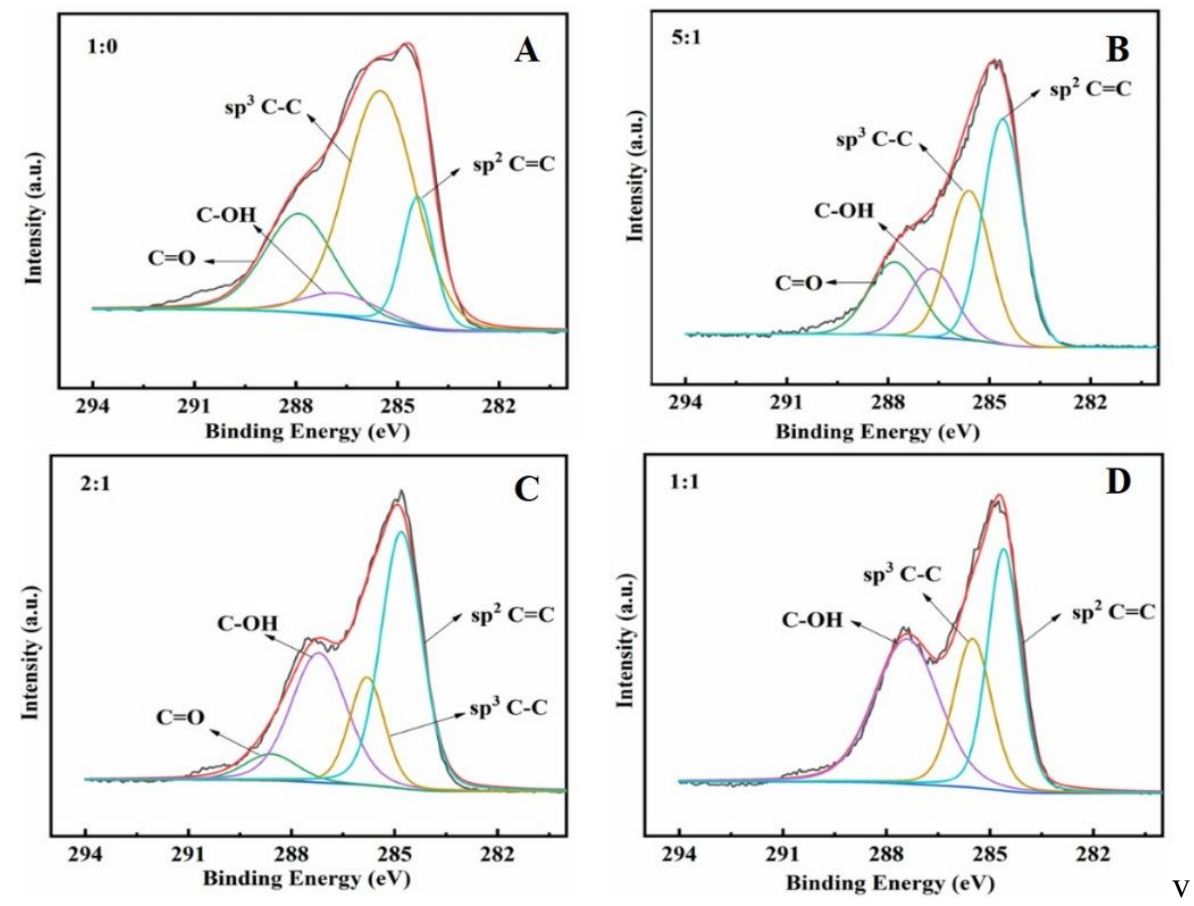

Figure S2. XPS C 1s, core-level spectrum of TA-APTES coated membranes with different

TA/APTES volume ratios: (A) 1:0, (B) 5:1, (C) 2:1, (C) 1:1.

As seen in Figure S1 and Table S1, when only TA is coated on the membrane, the surface roughness reduces since some "valleys" are filled by TA coating, while for the TA-APTES coated membrane, the surface roughness increased significantly because a large amount of nanoparticles are formed on the membrane until the TA/APTES ratio decreases to 1:1. Surprisingly, the surface roughness of the modified membrane increased again at a TA/APTES ratio of 1:5 as the coating layer was thin and not homogeneous (Figure 2H). Regarding the chemical property on the membrane surface, Figure S2 shows that with decrease of the TA/APTES volume ratio, the quinone content on the membrane surface declines, and the quinone group almost disappears when the TA/APTES volume ratio is $1: 1$. That was why the enzyme loading remarkably dropped at such TA/APTES ratio (Figure 3A).

To further demonstrate whether the TA-APTES coating and HRP were successfully loaded onto the membrane surface, we tested the zeta potential of the nylon membrane before and after coating/enzyme loading. As shown in Figure S3, the negative charge on the membrane after the TA-APTES coating significantly increases and then it decreases a little after HRP immobilization 
compared with the pristine membrane. It can be seen in EDX image (Figure S4A) that Si and S elements are detected on the Nylon-TA-APTES-HRP membrane surface (Figure S4A). Without doubt, Si element is derived from APTES and $\mathrm{S}$ element belongs to amino acids of HRP. Distribution of the immobilized HRP on the surface of the Nylon-TA-APTES membrane was visualized by confocal laser scanning microscopy (CLSM). As shown in Figure S4B, HRP-RhB (red points) has been successfully immobilized on the membrane and its distribution is quite even.

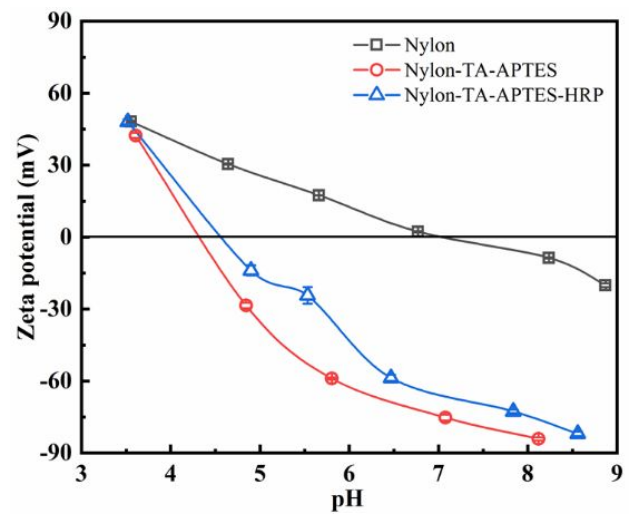

Figure S3. Zeta potential of the pristine and functionalized nylon membranes.
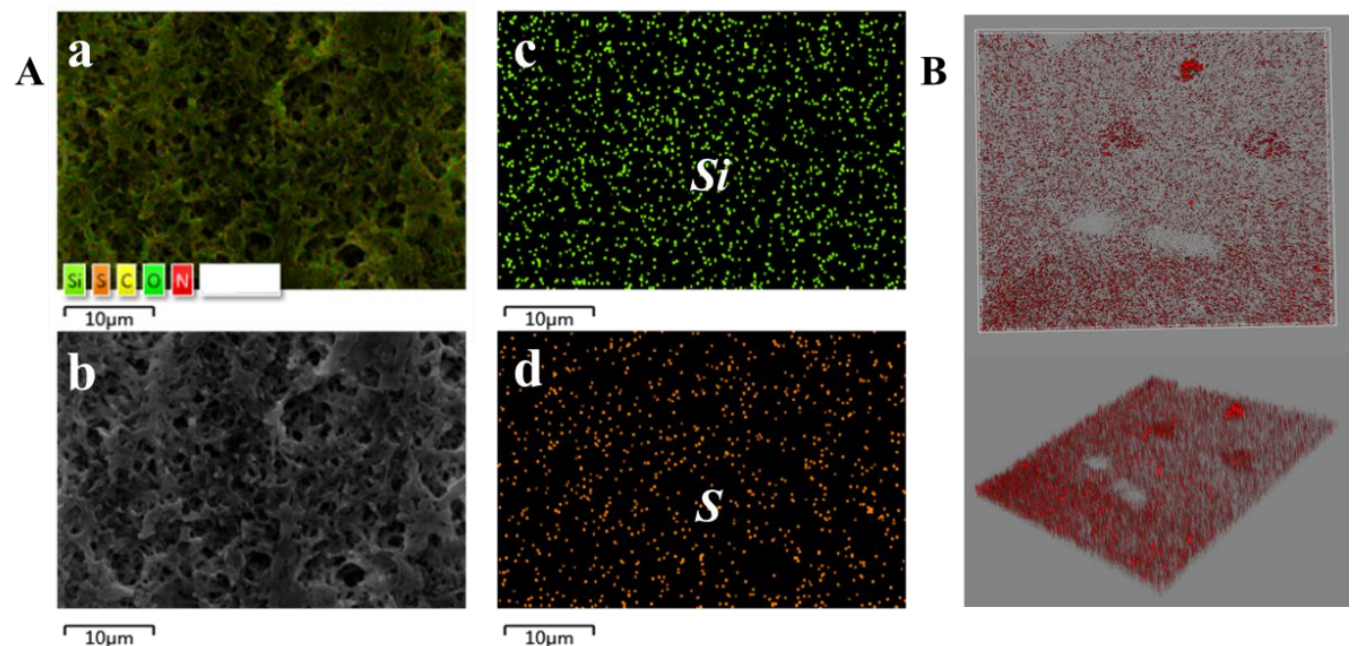

$\longdiv { 1 0 \mu \mathrm { m } }$

Figure S4. (A) EDX spectra of the nylon membrane with TA-APTES coating and immobilized HRP (a. EDS layered image. b. Electronic image. $\mathrm{c}$ and d are the distributions of the elements Si and S), (B) CLSM images of the nylon membrane with TA-APTES coating and immobilized HRP. The functional groups of the nylon, nylon-TA-APTES and nylon-TA-APTES-HRP 
membranes were investigated by FTIR spectra. As shown in Figure S5A, the FTIR spectrum of nylon membrane has a broad band at $3298 \mathrm{~cm}^{-1}$ assigned to the overlapping of $\mathrm{O}-\mathrm{H}$ stretching 8 . The band at $1534 \mathrm{~cm}^{-1}$ is attributed to the $\mathrm{N}-\mathrm{H}$ bending (amide II). Compared with the pristine nylon membrane, some new absorption signals appeared on the nylon-TA-APTES membrane. The peak at $1718 \mathrm{~cm}^{-1}$ should be due to the $\mathrm{C}=\mathrm{O}$ vibration. The $\mathrm{C}=\mathrm{O}$ groups on the nylon-TA-APTES membrane should be derived from the quinone that resulted from the oxidation of the TA molecules ${ }^{9-10}$. The peak at $1039 \mathrm{~cm}^{-1}$ and $794 \mathrm{~cm}^{-1}$ should be ascribed to the Si-O vibration ${ }^{11}$. The Si-O groups was derived from the hydrolysis of APTES. The emergence of new peaks demonstrates the successful coating of TA-APTES. As shown in Figure S5B, the O content on the membrane increases after the TA-APTES coating and enzyme loading, which is caused by a large amount of oxygen-containing functional groups on TA/APTES and enzyme. It is also found that new $\mathrm{Si}$ and $\mathrm{S}$ spectrums emerge for the modified membranes, confirming the successful TA-APTES coating and enzyme loading.
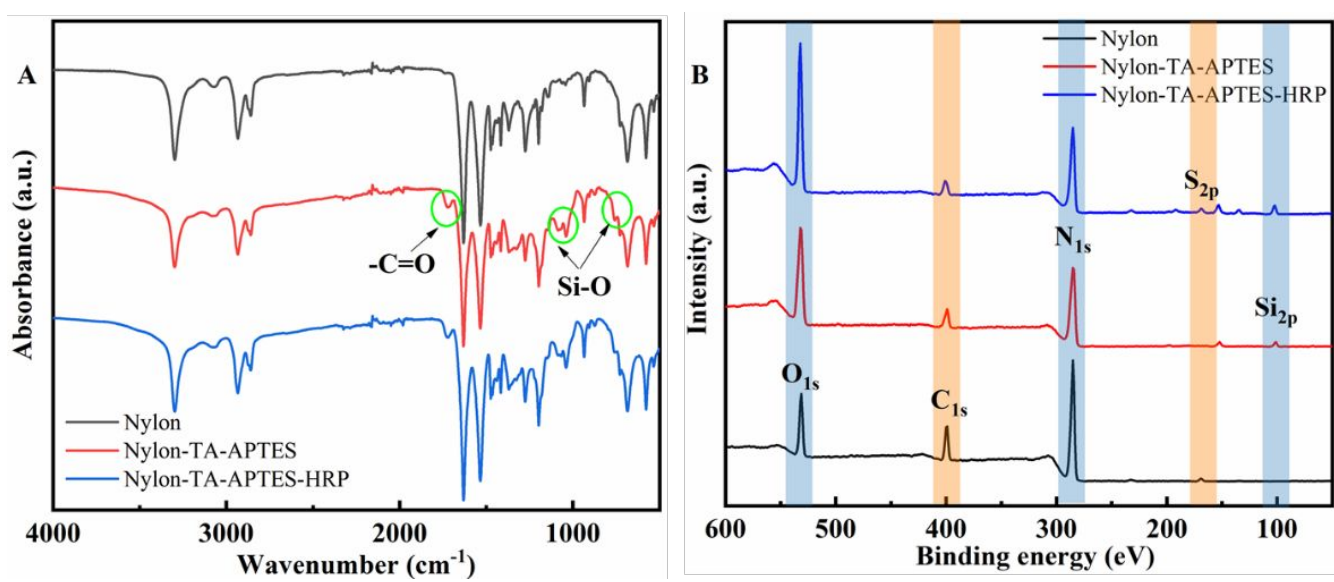

Figure S5. (A) FTIR spectra and (B) XPS results of the pristine and functionalized nylon membranes.

\section{REFERENCES}

1. Zhou, F.; Luo, J.; Qi, B.; Chen, X.; Wan, Y., Horseradish Peroxidase Immobilized on Multifunctional Hybrid Microspheres for Aflatoxin B1 Removal: Will Enzymatic Reaction be Enhanced by Adsorption? Ind. Eng. Chem. Res. 2019, 58 (27), 11710-11719.

2. Huang, X.-J.; Ge, D.; Xu, Z.-K., Preparation and characterization of stable chitosan nanofibrous membrane for lipase immobilization. Eur. Polym. J. 2007, 43 (9), 3710-3718. 

2007, $100(3), 964-971$.

4. Dai, Y.; Yao, J.; Song, Y.; Liu, X.; Wang, S.; Yuan, Y., Enhanced performance of immobilized laccase in electrospun fibrous membranes by carbon nanotubes modification and its application for bisphenol A removal from water. J. Hazard. Mater. 2016, 317, 485-493.

5. Bayramoglu, G.; Doz, T.; Ozalp, V. C.; Arica, M. Y., Improvement stability and performance of invertase via immobilization on to silanized and polymer brush grafted magnetic nanoparticles. Food Chem. 2017, 221, 1442-1450.

6. Li, S.; Luo, J.; Wan, Y., Regenerable biocatalytic nanofiltration membrane for aquatic micropollutants removal. J. Membr. Sci. 2018, 549, 120-128. immobilized on nano-copper incorporated electrospun fibrous membrane-high efficiency, stability and reusability. Chem. Eng. J. 2017, 326, 647-655. 8. Pan, L.; Wang, H.; Wu, C.; Liao, C.; Li, L., Tannic-acid-coated polypropylene membrane as a separator for lithium-ion batteries. ACS Appl. Mater. Interfaces 2015, 7 (29), 16003-16010. 9. Li, Q.; Liao, Z.; Fang, X.; Wang, D.; Xie, J.; Sun, X.; Wang, L.; Li, J., Tannic acid-polyethyleneimine crosslinked loose nanofiltration membrane for dye/salt mixture separation. J. Membr. Sci. 2019, 584, 324-332. 10. Wang, Z.; Han, M.; Zhang, J.; He, F.; Xu, Z.; Ji, S.; Peng, S.; Li, Y., Designing preferable functional materials based on the secondary reactions of the hierarchical tannic acid (TA)-aminopropyltriethoxysilane (APTES) coating. Chem. Eng. J. 2019, 360, 299-312. H., APTES-functionalized thin-walled porous $\mathrm{WO}_{3}$ nanotubes for highly selective sensing of $\mathrm{NO}_{2}$ in a polluted environment. J. Mater. Chem. A 2018, 6 (23), 10976-10989. 